\title{
Esterification of camphene over heterogeneous heteropoly acid catalysts: Synthesis of isobornyl carboxylates
}

\author{
Augusto L.P. de Meireles ${ }^{a}$, Kelly A. da Silva Rocha ${ }^{b}$, Ivan V. Kozhevnikov ${ }^{c}$, Elena V. Gusevskaya ${ }^{a, *}$ \\ a Departamento de Química, Universidade Federal de Minas Gerais, 31270-901 Belo Horizonte, MG, Brazil \\ b Departamento de Química, Universidade Federal de Ouro Preto, 35400-000 Ouro Preto, MG, Brazil \\ c Department of Chemistry, University of Liverpool, Liverpool L69 7ZD, UK
}

\section{A R T I C L E I N F O}

\section{Article history:}

Received 16 August 2011

Received in revised form

21 September 2011

Accepted 25 September 2011

Available online 1 October 2011

\section{Keywords:}

Biomass-based feedstock

Esterification

Camphene

Heterogeneous acid catalysis

Heteropoly acid

\begin{abstract}
A B S T R A C T
Silica supported $\mathrm{H}_{3} \mathrm{PW}_{12} \mathrm{O}_{40}(\mathrm{PW})$, the strongest heteropoly acid in the Keggin series, is an active and environmentally friendly solid acid catalyst for liquid-phase esterification of camphene, a renewable biomass-based substrate, with $C_{2}, C_{4}$ and $C_{6}$ short-chain fatty acids. The reaction provides isobornyl carboxylates, useful as fragrances, in virtually $100 \%$ selectivity and $80-90 \%$ yield. The reaction is equilibrium-controlled and occurs under mild conditions with a catalyst turnover number of up to 3000 The use of hydrocarbon solvent prevents PW from leaching to allow easy catalyst recovery. The catalyst can be reused several times without loss of activity and selectivity.
\end{abstract}

(c) 2011 Elsevier B.V. All rights reserved.

\section{Introduction}

Terpenes are the main component of essential oils of many plants and flowers and represent an important renewable hydrocarbon feedstock for fine chemical industry, in particular, for the synthesis of flavors and fragrances $[1,2]$. Various terpenic ingredients of fragrance compositions are commercially produced by acid-catalyzed transformations of abundant mono- and sesquiterpenes. In these processes, mineral acids are still used as homogeneous catalysts, which results in serious technological and environmental problems. The development of efficient solid acid catalysts for the conversion of terpenes can contribute significantly to valorization of essential oils.

Heteropoly acids (HPAs) of the Keggin series are well known as promising acid catalysts for the clean synthesis of fine and specialty chemicals $[3,4]$. Due to their stronger acidity, HPAs usually show higher catalytic activities than the conventional acid catalysts, such as mineral acids, ion-exchange resins, mixed oxides and zeolites. In contrast to mineral acids, HPAs do not promote undesirable side reactions, such as sulfonation and chlorination, as well as cause less corrosion problems. In our previous studies, HPAs have been

\footnotetext{
* Corresponding author. Tel.: +55 31 34095741; fax: +55 3134095700 .

E-mail address: elena@ufmg.br (E.V. Gusevskaya).
}

used as catalysts for various transformations of terpenoids, such as isomerization [5-8] and acetoxylation [9-11], including the acetoxylation and hydration of camphene [10]. Through acid-catalyzed addition of water and carboxylic acids, camphene can be converted to isoborneol and its esters, respectively, which possess a strong characteristic fragrance and are used in soap formulations, cosmetic perfumes and pharmaceutical products making popular pine and fruit-berry aromas almost identical to the natural ones [1,12]. Isoborneol is also used for the production of synthetic camphor [1].

Since the equilibrium of camphene hydration is shifted towards the reagents, only low yields of isoborneol have been obtained in this reaction $[13,14]$. On the other hand, the acetoxylation of camphene, which is less strictly equilibrium-controlled, can result in excellent yields of the commercially important pine-fragranced isobornyl acetate [10,15-17]. A number of solid acid catalysts, such as zeolites [15,18], surface-functionalized silica [19] and sulfonated polystyrene resins [16,17], have been used for the acetoxylation of camphene. In order to shift the equilibrium and obtain isobornyl acetate in high yields, acetic acid is usually used as a solvent. Such conditions, however, are hardly suitable for solid HPA catalysts due to high solubility of HPAs in polar solvents. HPAs, including $\mathrm{H}_{3} \mathrm{PW}_{12} \mathrm{O}_{40}(\mathrm{PW})$, have been used as homogeneous catalysts for the hydration $[13,14,20]$ and acetoxylation [10] of camphene, albeit with a complicated catalyst recovery. In our previous work, silica-supported PW has been applied as a heterogeneous catalyst for the solvent-free acetoxylation of camphene, with easy catalyst 
recovery, but yielding less than $30 \%$ of isobornyl acetate [10]. This is because the concentration of acetic acid should be kept low enough to prevent PW leaching from the catalyst.

Here we attempt to develop an efficient heterogeneous process for camphene esterification with $C_{2}, C_{4}$ and $C_{6}$ short-chain carboxylic acids in liquid phase using as a catalyst silica-supported $\mathrm{H}_{3} \mathrm{PW}_{12} \mathrm{O}_{40}$ (PW), the strongest HPA in the Keggin series. This is achieved by performing the reaction in a non-polar hydrocarbon solvent containing dissolved camphene and carboxylic acid in a molar ratio of 1:5-1:10. Under such conditions, the catalyst is found to be stable enough towards PW leaching, and reaction equilibrium appears to be shifted towards the product to allow high yields of isobornyl esters to be obtained. To our knowledge, no attempt to use HPA catalysts for the esterification of camphene has been made so far, except for our previous work on the camphene acetoxylation [10].

\section{Experimental}

\subsection{Chemicals}

All chemicals were purchased from commercial sources and used as received, unless otherwise stated. $\mathrm{H}_{3} \mathrm{PW}_{12} \mathrm{O}_{40}$ hydrate was from Aldrich and Aerosil 300 silica from Degussa.

\subsection{Characterization techniques}

${ }^{31} \mathrm{P}$ MAS NMR spectra were recorded at room temperature and $4 \mathrm{kHz}$ spinning rate on a Bruker Avance DSX 400 NMR spectrometer using $85 \% \mathrm{H}_{3} \mathrm{PO}_{4}$ as a reference. Powder X-ray diffraction (XRD) of the catalysts was performed on a Rigaku Geigerflex-3034 diffractometer with $\mathrm{Cu} \mathrm{K \alpha}$ radiation. The textural characteristics were determined from nitrogen physisorption measured on a Micromeritics ASAP 2000 instrument at $77 \mathrm{~K}$. Tungsten and phosphorus content in the catalysts was determined by inductively coupled plasma (ICP atomic emission spectroscopy) on a Spectro Ciros CCD spectrometer.

\subsection{Catalyst preparation and characterization}

The $20 \mathrm{wt} \% \mathrm{H}_{3} \mathrm{PW}_{12} \mathrm{O}_{40} / \mathrm{SiO}_{2}$ catalysts $\left(\mathrm{PW} / \mathrm{SiO}_{2}\right)$ was prepared by impregnating Aerosil $300\left(\mathrm{~S}_{\mathrm{BET}}, 300 \mathrm{~m}^{2} \mathrm{~g}^{-1}\right)$ with an aqueous PW solution followed by calcination at $130^{\circ} \mathrm{C} / 0.2-0.3$ Torr for $1.5 \mathrm{~h}$, as described elsewhere [21]. The PW content determined by ICP was $20 \mathrm{wt} \%$. The specific surface area of the fresh catalyst determined by the BET method was $200 \mathrm{~m}^{2} \mathrm{~g}^{-1}$. The average pore diameter and the single point total pore volume were $144 \AA$ and $0.53 \mathrm{~cm}^{3} \mathrm{~g}^{-1}$, respectively. After reaction the surface area slightly reduced to $170-180 \mathrm{~m}^{2} \mathrm{~g}^{-1}$ probably due to deposition of oligomers, whereas the porosity did not change significantly after reaction. The ${ }^{31} \mathrm{P}$ MAS NMR spectra of fresh as well as spent catalysts displayed only a single peak at ca. $-15 \mathrm{ppm}$ characteristic of PW confirming the integrity of the Keggin structure [22]. From XRD, the catalysts included finely dispersed PW on the silica surface, with a small amount PW crystalline phase also present. The acid strength of silica-supported PW was characterized calorimetrically using ammonia and pyridine adsorption and discussed previously [23].

\subsection{Catalytic reactions}

The reactions were carried out in a glass reactor equipped with a magnetic stirrer and a condensor. In a typical run, a mixture (total volume of $5.0 \mathrm{~mL}$ ) of camphene $(0.35-2.25 \mathrm{mmol}$, 0.07-0.45 M), carboxylic acid (3.5-22.5 mmol, 0.7-4.5 M), dodecane (0.5-1.0 mmol, 0.10-0.2 M, GC internal standard) and $\mathrm{PW} / \mathrm{SiO}_{2}$
(10-50 mg, 0.7-3.5 $\mu \mathrm{mol}$ of PW) in a specified solvent was intensely stirred under air at a specified temperature $\left(40-80^{\circ} \mathrm{C}\right)$. The reactions were followed by gas chromatography (GC) using a Shimadzu 17 instrument fitted with a Carbowax 20 M capillary column and a flame ionization detector. At indicated reaction times, stirring was stopped and after quick catalyst settling down aliquots were taken and analyzed by CG. The mass balance, product selectivity and yield were calculated using dodecane as internal standard. Any difference in mass balance was attributed to the formation of oligomers, which were GC unobservable.

Catalyst recycling experiments were performed as follows: after the reaction, the catalyst was centrifuged, washed with hexane and reused. To control catalyst leaching and the possibility of a homogeneous reaction, the catalyst was removed by centrifugation of the reaction mixture at the reaction temperature to avoid re-adsorption of active components onto silica, then the supernatant was added with a fresh portion of substrate, if necessary, and allowed to react on. No further reaction was observed in such experiments, indicating absence of PW leaching.

Isoborneol acetate (2) was identified by GC/MS (Shimadzu QP2010-PLUS instrument, $70 \mathrm{eV}$ ) by comparison with an authentic sample. The esters 3 and $\mathbf{4}$ were separated by a column chromatography (silica gel 60) using mixtures of hexane and $\mathrm{CH}_{2} \mathrm{Cl}_{2}$ as eluents and identified by GC-MS, ${ }^{1} \mathrm{H}$, and ${ }^{13} \mathrm{C}$ NMR. The ${ }^{1} \mathrm{H}$ and ${ }^{13} \mathrm{C}$ NMR signals were assigned using bidimensional techniques. NMR spectra were recorded in $\mathrm{CDCl}_{3}$ using a Bruker $400 \mathrm{MHz}$ spectrometer, with TMS as an internal standard. Mass spectra were obtained on a Shimadzu QP2010-PLUS instrument operating at $70 \mathrm{eV}$.

Data for isobornyl acetate 2: MS (m/z/rel.int.): 154/10; 136/47; 121/50; 108/25; 95/100; 93/48. ${ }^{1} \mathrm{H}$ NMR, $\delta_{\mathrm{H}}: 0.83\left(\mathrm{~s}, 3 \mathrm{H}, \mathrm{C}^{8} \mathrm{H}\right)$; $0.84\left(\mathrm{~s}, 3 \mathrm{H}, \mathrm{C}^{10} \mathrm{H}_{3}\right) ; 0.98\left(\mathrm{~s}, 3 \mathrm{H}, \mathrm{C}^{9} \mathrm{H}_{3}\right) ; 1.05-1.15\left(\mathrm{~m}, 1 \mathrm{H}, \mathrm{C}^{5} \mathrm{HH}\right)$; $1.10-1.20\left(\mathrm{~m}, 1 \mathrm{H}, \mathrm{C}^{6} \mathrm{HH}_{\mathrm{ax}}\right) ; 1.50-1.60\left(\mathrm{~m}, 1 \mathrm{H}, \mathrm{C}^{6} \mathrm{H}_{\mathrm{eq}} \mathrm{H}\right) ; 1.65-1.75$ $\left(\mathrm{m}, 1 \mathrm{H}, \mathrm{C}^{5} \mathrm{HH}\right) ; 1.65-1.75\left(\mathrm{~m}, 1 \mathrm{H}, \mathrm{C}^{4} \mathrm{H}\right) ; 1.75-1.85\left(\mathrm{~m}, 2 \mathrm{H}, \mathrm{C}^{3} \mathrm{H}_{2}\right)$; $2.08\left(\mathrm{~s}, 1 \mathrm{H}, \mathrm{C}^{12} \mathrm{H}_{3}\right) ; 4.67\left(\mathrm{dd}, 1 \mathrm{H},{ }^{3} \mathrm{~J}=8.0\right.$ and $\left.3.0 \mathrm{~Hz}, \mathrm{C}^{2} \mathrm{H}\right) .{ }^{13} \mathrm{C} \mathrm{NMR}$, $\delta_{\mathrm{C}}$ : $11.38\left(C^{10}\right), 19.87\left(C^{9}\right), 20.17\left(C^{8}\right), 21.31\left(C^{12}\right), 27.02\left(C^{5}\right), 33.72$ $\left(C^{6}\right), 38.75\left(C^{3}\right), 44.99\left(C^{4}\right), 46.94\left(C^{7}\right), 48.63\left(C^{1}\right), 80.94\left(C^{2}\right), 170.66$ $\left(C^{11}\right)$.

Data for isobornyl butyrate 3: MS (m/z/rel.int.): 154/22, 137/20, $136 / 89,121 / 67,110 / 44,109 / 40,108 / 50,95 / 100,93 / 55,71 / 89$, 69/25. ${ }^{1} \mathrm{H} \mathrm{NMR}, \delta_{\mathrm{H}}: 0.84\left(\mathrm{~s}, 6 \mathrm{H}, \mathrm{C}^{8} \mathrm{H}_{3}, \mathrm{C}^{10} \mathrm{H}_{3}\right) ; 0.96\left(\mathrm{t}, 3 \mathrm{H},{ }^{3} \mathrm{~J}=7.4 \mathrm{~Hz}\right.$, $\left.\mathrm{C}^{14} \mathrm{H}_{3}\right) ; 0.98\left(\mathrm{~s}, 3 \mathrm{H}, \mathrm{C}^{9} \mathrm{H}_{3}\right) ; 1.05-1.10\left(\mathrm{~m}, 1 \mathrm{H}, \mathrm{C}^{5} \mathrm{HH}\right) ; 1.10-1.18(\mathrm{~m}$, $\left.1 \mathrm{H}, \mathrm{C}^{6} \mathrm{H} \mathrm{H}_{\mathrm{ax}}\right) ; 1.50-1.56\left(\mathrm{~m}, 1 \mathrm{H}, \mathrm{C}^{6} \mathrm{H}_{\mathrm{eq}} \mathrm{H}\right) ; 1.58-1.64\left(\mathrm{~m}, 2 \mathrm{H}, \mathrm{C}^{13} \mathrm{H}_{2}\right)$; $1.64-1.70\left(\mathrm{~m}, 1 \mathrm{H}, \mathrm{C}^{5} \mathrm{HH}\right) ; 1.70-1.75\left(\mathrm{~m}, 2 \mathrm{H}, \mathrm{C}^{4} \mathrm{H}, \mathrm{C}^{3} \mathrm{HH}\right) ; 1.75-1.85$ $\left(\mathrm{m}, 1 \mathrm{H}, \mathrm{C}^{3} \mathrm{HH}\right) ; 2.26\left(\mathrm{t}, 2 \mathrm{H},{ }^{3} \mathrm{~J}=7.4 \mathrm{~Hz}, \mathrm{C}^{12} \mathrm{H}_{2}\right) ; 4.67\left(\mathrm{dd}, 1 \mathrm{H},{ }^{3} \mathrm{~J}=8.0\right.$ and $\left.3.2 \mathrm{~Hz}, \mathrm{C}^{2} H\right) .{ }^{13} \mathrm{C}$ NMR, $\delta_{\mathrm{C}}$ : $11.70\left(\mathrm{C}^{10}\right), 13.98\left(\mathrm{C}^{14}\right), 18.82\left(\mathrm{C}^{13}\right)$, $20.15\left(C^{9}\right), 20.39\left(C^{8}\right), 27.32\left(C^{5}\right), 34.05\left(C^{6}\right), 37.04\left(C^{12}\right), 39.14\left(C^{3}\right)$, $45.34\left(C^{4}\right), 47.18\left(C^{7}\right), 48.89\left(C^{1}\right), 80.99\left(C^{2}\right), 173.51\left(C^{11}\right)$.

Data for isobornyl caprylate 4: MS (m/z/rel.int.): 154/20, 137/32, $136 / 100,121 / 92,110 / 3,109 / 50,108 / 60,107 / 26,99 / 76,96 / 95$, 95/92, 93/96, 92/25, 81/36, 79/26, 71/60, 67/25. ${ }^{1} \mathrm{H}$ NMR, $\delta_{\mathrm{H}}$ : 0.77 (s, 6H, C $\left.{ }^{8} \mathrm{H}_{3}, \mathrm{C}^{10} \mathrm{H}_{3}\right) ; 0.82\left(\mathrm{t}, 3 \mathrm{H},{ }^{3} \mathrm{~J}=6.8 \mathrm{~Hz}, \mathrm{C}^{16} \mathrm{H}_{3}\right) ; 0.91$ (s, $\left.3 \mathrm{H}, \mathrm{C}^{9} \mathrm{H}_{3}\right)$; 0.96-1.04 (m, $\left.1 \mathrm{H}, \mathrm{C}^{13} \mathrm{HH}\right) ; 1.06-1.12\left(\mathrm{~m}, 1 \mathrm{H}, \mathrm{C}^{6} \mathrm{HH}_{\mathrm{ax}}\right)$; $1.10-1.26\left(\mathrm{~m}, 2 \mathrm{H}, \mathrm{C}^{5} \mathrm{H}_{2}\right) ; 1.22-1.26\left(\mathrm{~m}, 2 \mathrm{H}, \mathrm{C}^{15} \mathrm{H}_{2}\right) ; 1.42-1.50(\mathrm{~m}$, $\left.1 \mathrm{H}, \mathrm{C}^{6} \mathrm{H}_{\mathrm{eq}} \mathrm{H}\right) ; 1.50-1.56\left(\mathrm{~m}, 2 \mathrm{H}, \mathrm{C}^{14} \mathrm{H}_{2}\right) ; 1.58-1.68\left(\mathrm{~m}, 3 \mathrm{H}, \mathrm{C}^{13} \mathrm{HH}\right.$, $\left.\mathrm{C}^{4} \mathrm{H}, \mathrm{C}^{3} \mathrm{HH}\right) ; 1.68-1.76\left(\mathrm{~m}, 1 \mathrm{H}, \mathrm{C}^{3} \mathrm{HH}\right) ; 2.20\left(\mathrm{t}, 2 \mathrm{H},{ }^{3} \mathrm{~J}=7.4 \mathrm{~Hz}, \mathrm{C}^{12} \mathrm{H}_{2}\right)$; $4.59\left(\mathrm{dd}, 1 \mathrm{H},{ }^{3} \mathrm{~J}=7.6\right.$ and $\left.3.2 \mathrm{~Hz}, \mathrm{C}^{2} \mathrm{H}\right) .{ }^{13} \mathrm{CNMR}, \delta_{\mathrm{C}}: 11.43\left(\mathrm{C}^{10}\right), 13.88$ $\left(C^{16}\right), 19.83\left(C^{9}\right), 20.12\left(C^{8}\right), 22.31\left(C^{15}\right), 24.75\left(C^{14}\right), 27.05\left(C^{13}\right)$, $31.32\left(C^{5}\right), 33.78\left(C^{6}\right), 34.80\left(C^{12}\right), 38.87\left(C^{3}\right), 45.07\left(C^{4}\right), 46.92\left(C^{7}\right)$, $48.63\left(C^{1}\right), 80.75\left(C^{2}\right), 173.46\left(C^{11}\right)$.

\section{Results and discussion}

The results on camphene (1) esterification with acetic acid (5-10 fold excess) in the presence of $\mathrm{PW} / \mathrm{SiO}_{2}$ in cyclohexane solution at $40-80^{\circ} \mathrm{C}$ are presented in Table 1 . The reaction occurred 
Table 1

Esterification of camphene with acetic acid catalyzed by $20 \mathrm{wt} \% \mathrm{PW} / \mathrm{SiO}_{2}$. ${ }^{\mathrm{a}}$

\begin{tabular}{|c|c|c|c|c|c|c|c|c|}
\hline Run & Camphene (mmol) & HOAc (mmol) & Catalyst $(\mathrm{mg} / \mu \mathrm{mol}$ of PW) & $T\left({ }^{\circ} \mathrm{C}\right)$ & Time (h) & Conversion (\%) & Selectivity to 2 (\%) & $\mathrm{TON}^{\mathrm{b}}$ \\
\hline \multirow[t]{2}{*}{1} & 0.35 & 3.5 & $50 / 3.5$ & 60 & 1 & 67 & 100 & 70 \\
\hline & & & & & 3 & 70 & 100 & \\
\hline \multirow[t]{2}{*}{2} & 0.75 & 3.5 & $50 / 3.5$ & 60 & 1 & 68 & 100 & 150 \\
\hline & & & & & 3 & 70 & 100 & \\
\hline \multirow[t]{2}{*}{$3^{c}$} & 0.75 & 7.5 & $50 / 3.5$ & 60 & 1 & 78 & 100 & 170 \\
\hline & & & & & 3 & 80 & 100 & \\
\hline \multirow[t]{2}{*}{4} & 1.00 & 10.0 & $50 / 3.5$ & 40 & 1 & 79 & 100 & 240 \\
\hline & & & & & 3 & 83 & 100 & \\
\hline 5 & 1.00 & 10.0 & None & 60 & 6 & 0 & & \\
\hline \multirow[t]{2}{*}{6} & 0.75 & 7.5 & $10 / 0.7$ & 60 & 2 & 78 & 100 & 870 \\
\hline & & & & & 4 & 81 & 100 & \\
\hline \multirow[t]{2}{*}{7} & 2.25 & 22.5 & $10 / 0.7$ & 60 & 2 & 80 & 100 & 2892 \\
\hline & & & & & 4 & 90 & 100 & \\
\hline \multirow[t]{2}{*}{$8^{d}$} & 2.25 & 22.5 & $10 / 0.7$ & 60 & 0.15 & 24 & 100 & 800 \\
\hline & & & & & 3 & 25 & 100 & \\
\hline \multirow[t]{2}{*}{$9^{e}$} & 2.25 & 22.5 & $10 / 0.7$ & 60 & 2 & 83 & 100 & 2828 \\
\hline & & & & & 4 & 88 & 100 & \\
\hline $10^{\mathrm{e}, \mathrm{f}}$ & 2.25 & 22.5 & $10 / 0.7$ & 60 & 4 & $<2 \%$ & & \\
\hline \multirow[t]{2}{*}{$11^{\mathrm{e}}$} & 2.25 & 22.5 & $10 / 0.7$ & 80 & 0.5 & 75 & 100 & 2410 \\
\hline & & & & & 3 & 75 & 100 & \\
\hline
\end{tabular}

a Reactions were carried out in cyclohexane as a solvent, with the total volume of the reaction mixture of $5.0 \mathrm{~mL}$. Conversion and selectivity were determined by GC.

b TON in moles of substrate converted per mole of a total amount of PW in catalyst.

c The catalyst was reused twice without significant loss of activity and selectivity.

d After 10 min the catalyst was separated by centrifugation, the supernatant was allowed to react further, with no further conversion observed thereupon.

e In isooctane as solvent.

f After run 9, the catalyst was removed, the solution was recharged with fresh substrate (2.25 mmol) and the reaction was allowed to proceed further, with no further conversion observed thereupon.

with $100 \%$ selectivity to isobornyl acetate (2), no other products being observed (Scheme 1 ). The reaction was not complicated by oligomerization and isomerization, as often happens with terpenic compounds under acidic conditions. It is remarkable that no trace of borneol acetate, the endo-isomer of $\mathbf{2}$, was observed, which indicates high reaction stereoselectivity.

At $60^{\circ} \mathrm{C}$, nearly $70 \%$ of camphene converted to isobornyl acetate in $1 \mathrm{~h}$. After that the reaction became stagnant, indicating equilibrium control (Table 1 , run 1 ). With the same amount of catalyst, the reaction was equally efficient with a double substrate concentration, reaching again $70 \%$ camphene conversion at $100 \%$ selectivity to 2 (Table 1, run 2). When a larger (10 fold) excess of acetic acid was used, reaction equilibrium shifted towards the product, allowing a $78 \%$ conversion in $1 \mathrm{~h}$ (Table 1 , run 3 ). Carrying on the reaction for another $2 \mathrm{~h}$ did not change the conversion. After that the catalyst was separated by centrifugation and reused twice without significant loss of activity and selectivity. At a lower reaction temperature of $40^{\circ} \mathrm{C}$, a higher yield of isobornyl acetate $(83 \%)$ was obtained in $3 \mathrm{~h}$ (Table 1, run 4). Blank reactions, without any catalyst added or with pure silica, showed virtually no conversion of camphene in $6 \mathrm{~h}$ (Table 1 , run 5).

The suggestion that the incomplete conversion is due to equilibrium control rather than catalyst deactivation was further confirmed by running the reaction with much smaller amounts of catalyst (cf. runs 3 and 6, Table 1). Thus in run 6 with one fifth of the catalyst amount used in run 3 , the reaction reached the same conversion (78\%), albeit more slowly ( $2 \mathrm{~h}$ rather than $1 \mathrm{~h})$, as expected for the equilibrium-controlled reaction. This corresponds to a turnover number (TON) of 870 per mol of the total amount of PW in the catalyst. Considering that a part of acid sites may be located in the bulk of PW phase and hence not accessible to the substrate, the real efficiency of the surface active sites could be even higher.

Attempting to improve the yield of $\mathbf{2}$, we increased the initial concentration of camphene at a 1:10 camphene/acetic acid molar ratio. This gave a camphene conversion of $90 \%$ at $100 \%$ selectivity to 2 (90\% isobornyl acetate yield and TON about 3000 ) (Table 1, run 7).

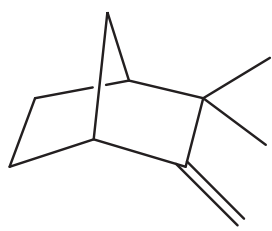

1

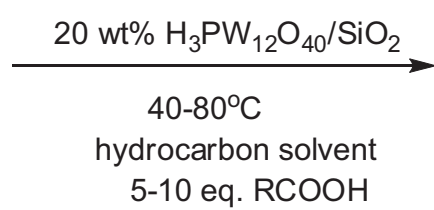

$$
\begin{aligned}
& 2 \mathrm{R}={ }^{12} \mathrm{CH}_{3} \\
& 3 \mathrm{R}={ }^{12} \mathrm{CH}_{2}{ }^{13} \mathrm{CH}_{2}{ }^{14} \mathrm{CH}_{3} \\
& 4 \mathrm{R}={ }^{12} \mathrm{CH}_{2}{ }^{13} \mathrm{CH}_{2}{ }^{14} \mathrm{CH}_{2}{ }^{15} \mathrm{CH}_{2}{ }^{16} \mathrm{CH}_{3}
\end{aligned}
$$


Table 2

Esterification of camphene with carboxylic acids catalyzed by $20 \mathrm{wt} \% \mathrm{PW} / \mathrm{SiO}_{2}{ }^{\text {at }}$

\begin{tabular}{|c|c|c|c|c|c|c|}
\hline Run & Acid (mmol) & $\begin{array}{l}\text { Catalyst } \\
(\mathrm{mg} / \mu \mathrm{mol} \text { of } \\
\mathrm{PW})\end{array}$ & Time (h) & Conversion (\%) & $\begin{array}{l}\text { Selectivity to } 2 \text {, } \\
3 \text {, or } 4(\%)\end{array}$ & TON \\
\hline \multirow[t]{2}{*}{1} & Acetic (22.5) & $10 / 0.7$ & 2 & 83 & 100 & 2828 \\
\hline & & & 4 & 88 & 100 & \\
\hline \multirow[t]{2}{*}{2} & n-Butyric (11.2) & $10 / 0.7$ & 2 & 23 & 100 & 1670 \\
\hline & & & 7 & 52 & 100 & \\
\hline \multirow[t]{3}{*}{$3^{c}$} & n-Butyric (11.2) & $25 / 1.8$ & 2 & 69 & 100 & 1000 \\
\hline & & & 4 & 80 & 100 & \\
\hline & & & 6 & 80 & 100 & \\
\hline 4 & n-Butyric (11.2) & $50 / 3.5$ & 2 & 78 & 100 & 500 \\
\hline \multirow[t]{2}{*}{$5^{c}$} & n-Hexanoic (11.2) & $25 / 1.8$ & 2 & 33 & 100 & 575 \\
\hline & & & 4 & 46 & 100 & \\
\hline \multirow[t]{3}{*}{6} & n-Hexanoic (11.2) & $50 / 3.5$ & 2 & 65 & 100 & 515 \\
\hline & & & 3 & 80 & 100 & \\
\hline & & & 6 & 80 & 100 & \\
\hline
\end{tabular}

a Reaction conditions: $2.25 \mathrm{mmol}$ camphene, isooctane solvent, $5.0 \mathrm{~mL}$ total volume of the reaction mixture, $60^{\circ} \mathrm{C}$. Conversion and selectivity were determined by GC.

b TON in moles of substrate converted per mole of total amount of PW in catalyst.

c The catalyst was reused twice without significant loss of activity and selectivity.

Although PW is insoluble in non-polar solvents and poorly soluble in dry carboxylic acids, the presence of acetic acid in the reaction mixture could promote some PW leaching from the catalyst and hence initiate homogeneous catalysis by the dissolved PW. To examine any contribution of homogeneous catalysis, the catalyst was removed after 10 min reaction time by centrifugation and the supernatant was allowed reacting further (Table 1, run 8). No further substrate conversion was observed in this experiment, which shows that the reaction occurs by heterogeneous catalysis and homogeneous catalysis does not play any significant role in our system, implying the absence of substantial PW leaching from silica under reaction conditions used. In our previous studies of terpene reactions over $\mathrm{PW} / \mathrm{SiO}_{2}$ in cyclohexane, ICP analysis of the supernatant did not find any tungsten leaching from the catalyst [5]. The characterization of fresh versus spent catalysts (Section 2.3) did not reveal any significant change in the catalyst texture, nor did it show any structural alteration of the PW, as may be expected for this reaction occurring under mild conditions in non-polar hydrocarbon solvent.

The acetoxylation of camphene over $\mathrm{PW} / \mathrm{SiO}_{2}$ catalyst was also performed in isooctane. This yielded $88 \%$ of 2 , almost the same as in cyclohexane (Table 1, run 9 vs. run 7). Higher boiling point of isooctane (b.p. $99^{\circ} \mathrm{C}$ ) can be an advantage for practical applications as compared to cyclohexane (b.p. $81^{\circ} \mathrm{C}$ ). As expected, the reaction at $80^{\circ} \mathrm{C}$ was faster than at $60^{\circ} \mathrm{C}$; however, the equilibrium conversion decreased from 88 to $75 \%$ (cf. runs 9 and 11, Table 1). To control the leaching of PW, the catalyst after run 9 was removed from the reaction mixture which was then recharged with fresh substrate and allowed reacting further (Table 1, run 10). Practically no camphene conversion was observed after the catalyst removal. This result also supports the above conclusion regarding the reaction occurring by heterogeneous catalysis and the absence of any significant PW leaching in our system.

The reaction can be carried out with other carboxylic acids to obtain the corresponding isobornyl carboxylates in good to excellent yields. These esters are also useful as fragrances similar to 2. Representative results obtained with the use of $n$-butyric and $n$-hexanoic ( $n$-caproic) acids are shown in Table 2 . For comparison, the results for acetic acid under similar conditions are also included in Table 2 (run 1 ). In the experiments with $n$-butyric and $n$-hexanoic acids, due to their higher molecular weights, smaller acid/camphene molar ratios (up to 5:1) were used to avoid PW leaching from the catalyst to the reaction mixture although it could result in lower product yields.

The reaction of camphene with $n$-butyric acid occurred much slower than with acetic acid, reaching a non-equilibrium camphene conversion of $52 \%$ in $7 \mathrm{~h}$ with a TON of 1670 (Table 2, run 2). To accelerate the reaction, we increased the amount of catalyst and attained a nearly equilibrium conversion of $80 \%$ in $1-2 \mathrm{~h}$ reaction time (Table 2, runs 3 and 4). After that the reaction became stagnant. This reaction gave isobornyl butyrate (3) (Scheme 1 ) in almost $100 \%$ selectivity. The product was isolated by a column chromatography and identified by GC-MS and NMR. The NOESY spectrum of 3 reveals that in this molecule the hydrogen $\mathrm{H}-2$ gives NOE with the hydrogen $\mathrm{H}-\mathrm{G}_{\mathrm{ax}}$ showing their spatial proximity. This clearly indicates the exo-configuration for $\mathbf{3}$, in which the carboxylic group at $\mathrm{C}-2$ and the hydrogen $\mathrm{H}-\mathrm{G}_{\mathrm{ax}}$ are at the opposite sides of the six-membered ring, as shown in Scheme 1.

The esterification of camphene with $n$-hexanoic acid is also feasible with the $\mathrm{PW} / \mathrm{SiO}_{2}$ catalyst (Table 2 , runs 5 and 6 ), although it went slower than with $n$-butyric acid (cf. runs 3 and 5, Table 2). With $n$-butyric acid, the reaction almost reached equilibrium in $4 \mathrm{~h}$, whereas with $n$-hexanoic acid only $46 \%$ camphene conversion was obtained within that time interval. Thus, the longer the hydrocarbon chain of carboxylic acid, the slower the camphene esterification, which can be plausibly explained by steric constraints. Under optimized conditions, isobornyl caprylate (4) was obtained with $80 \%$ yield in $3 \mathrm{~h}$ (Table 2 , run 6 ). This yield was also limited by equilibrium as the selectivity to 4 was virtually $100 \%$ and continuing the reaction beyond the $3 \mathrm{~h}$ interval did not increase the conversion any more. Unconverted camphene could be recovered during product separation. This, however, was not attempted in the present study. The catalyst separated after runs 3 and 5 was reused twice in the same reactions and showed nearly the same activity and selectivity.

Stereochemistry of ester $\mathbf{4}$ was also confirmed by a NOESY experiment. The results suggest that in $\mathbf{4}$ the hydrogen at $\mathrm{C}-2$ and the axial hydrogen at C-6 are at the same side of the cyclohexane ring, as shown in Scheme 1, because there is a strong correlation signal between $\mathrm{H}-2$ and $\mathrm{H}-6_{\mathrm{ax}}$. Thus, the obtained ester is exo-isomer, i.e. derived from isoborneol.

\section{Conclusions}

Heteropoly acid $\mathrm{H}_{3} \mathrm{PW}_{12} \mathrm{O}_{40}$ (PW) supported on silica is an efficient and environmentally friendly solid acid catalyst for the liquid-phase esterification of camphene with carboxylic acids under mild reaction conditions. This reaction is an effective route for the synthesis isobornyl carboxylates, potential fragrances possessing a strong characteristic aroma, starting from a renewable biomass-based substrate. The reaction yield is equilibrium-controlled, with ester selectivity of virtually $100 \%$. 
Under optimized conditions, the esters have been obtained in 80-90\% yield and up to $3000 \mathrm{PW}$ turnover number. The catalyst can be recovered and reused without loss of activity and selectivity.

\section{Acknowledgments}

Financial support and scholarships from CNPq, CAPES, FAPEMIG, and INCT-Catálise (Brazil) are acknowledged.

\section{References}

[1] W.E. Erman, Chemistry of Monoterpenes. An Encyclopedic Handbook, Marcel Dekker, New York, 1985.

[2] C. Sell, in: C. Sell (Ed.), The Chemistry of Fragrances: from Perfumer to Consumer, vol. 2, 2nd ed., RSC Publishing, Dorset, UK, 2006, 52-88.

[3] I.V. Kozhevnikov, Catalysts for Fine Chemicals, Catalysis by Polyoxometalates, vol. 2, Wiley, Chichester, 2002.

[4] T. Okuhara, N. Muzuno, M. Misono, Appl. Catal. A 222 (2001) 63-77.

[5] K.A. da Silva Rocha, I.V. Kozhevnikov, E.V. Gusevskaya, Appl. Catal. A 294 (2005) $106-110$.

[6] K.A. da Silva Rocha, P.A. Robles-Dutenhefner, E.M.B. Sousa, E.F. Kozhevnikova, I.V. Kozhevnikov, E.V. Gusevskaya, Appl. Catal. A 317 (2007) 171-174.

[7] K.A. da Silva Rocha, J.L. Hoehne, E.V. Gusevskaya, Chem. Eur. J. 14 (2008) 6166-6172.
[8] K.A. da Silva Rocha, P.A. Robles-Dutenhefner, I.V. Kozhevnikov, E.V. Gusevskaya, Appl. Catal. A 352 (2009) 188-192.

[9] P.A. Robles-Dutenhefner, K.A. da Silva, M.R.H. Siddiqui, I.V. Kozhevnikov, E.V. Gusevskaya, J. Mol. Catal. A 175 (2001) 33-42.

[10] K.A. da Silva, I.V. Kozhevnikov, E.V. Gusevskaya, J. Mol. Catal. A 192 (2003) 129-134.

[11] K.A. da Silva Rocha, N.V.S. Rodrigues, I.V. Kozhevnikov, E.V. Gusevskaya, Appl. Catal. A 374 (2010) 87-94.

[12] V.L. Fleisher, O.G. Vyglazov, V.A. Chuiko, S.A. Lamotkin, Khim. Rastitel'nogo Syr'ya 4 (2007) 61-64.

[13] M.A. Schwegler, H. van Bekkum, Bull. Soc. Chim. Belg. 99 (1990) 113-120.

[14] A.B. Radbil', M.V. Kulikov, T.N. Sokolova, V.R. Kartashov, V.I. Klimanskii, B.A. Radbil', B.A. Zolin, Russ. J. Appl. Chem. 73 (2000) 253-256.

[15] H. Liu, D. Jin, Q. Li, Z. Lan, Z. Fu, Linchan Huaxue Yu Gongye 16 (1996) 15-19.

[16] A. Tao, X. Jiang, Shanghai Huagong 33 (2008) 14-16.

[17] I.J. Dijs, H.L.F. van Ochten, A.J.M. van der Heijden, J.W. Geus, L.W. Jenneskens, Appl. Catal. A 241 (2003) 185-203.

[18] J.E. Castanheiro, I.M. Fonseca, A.M. Ramos, J. Vital, Catal. Commun. 9 (2008) 2205-2208.

[19] I.J. Dijs, H.L.F. van Ochten, C.A. van Walree, J.W. Geus, L.W. Jenneskens, J. Mol. Catal. A 188 (2002) 209-224.

[20] A.B. Radbil', M.V. Kulikov, T.N. Sokolova, V.R. Kartashov, B.A. Zolin, B.A. Radbil', Chem. Nat. Compd. 35 (1999) 524-528.

[21] I.V. Kozhevnikov, A. Sinnema, A.J.A. van der Weerdt, H. van Bekkum, J. Mol. Catal. A 120 (1997) 63-70.

[22] I.V. Kozhevnikov, Chem. Rev. 98 (1998) 171-198.

[23] E.F. Kozhevnikova, I.V. Kozhevnikov, J. Catal. 224 (2004) 164-169. 